\title{
Hypersensitivity pneumonitis in children
}

\author{
Maria Wawszczak ${ }^{1, A-D, F \oplus}$, Teresa Bielecka ${ }^{1, C, E-F \oplus}$, Maciej Szczukocki' ${ }^{2, D} \oplus$ \\ ${ }^{1}$ Department of Pediatric Pneumonology and Allergy, Medical University of Warsaw, Poland \\ ${ }^{2}$ Department of Paediatrics, Paediatric and Social Nursing, Institute of Nursing and Midwifery, Faculty of Medicine and \\ Health Sciences, Jan Kochanowski University, Kielce, Poland \\ A - Research concept and design, B - Collection and/or assembly of data, C - Data analysis and interpretation, \\ $D$ - Writing the article, E - Critical revision of the article, F - Final approval of article
}

Wawszczak M, Bielecka T, Szczukocki M. Hypersensitivity pneumonitis in children. Ann Agric Environ Med. 2021 ; 28(2): 214-219. doi: $10.26444 /$ aaem $/ 118830$

\section{Abstract}

Introduction. Hypersensitivity pneumonitis (HP) is one of the most common forms of interstitial lung disease in children. Due to its common association with occupational environment, it used to be considered an exclusively adult disease; however, hypersensitivity pneumonitis also affects the paediatric population, and is often associated with exposure to antigens in the home environment and with the pastime activities of children.

Objective. The aim of the study is to present the current state of knowledge on hypersensitivity pneumonitis in children with a focus on the peculiarities of diagnostic investigation and management of the disease in this age group. The study includes a case report of the disease in a child.

State of knowledge. In children, the most common factors causing HP are avian and fungal antigens present in the home environment. Diagnosis is based on the co-occurrence of characteristic clinical presentation, radiographic and pulmonary function tests findings, and a history of exposure to a potential triggering antigen. The main strategy in the management of HP is to eliminate the trigger factor with the use of a systemic corticosteroids therapy in severe or advanced cases.

Conclusions. Due to the risk of irreversible changes in the respiratory tract, an early diagnosis is very important. A quick identification of the trigger factor and its elimination from the patient's environment makes it possible to apply a less aggressive treatment, and to improve the patient's prognosis. Unfortunately, due to its infrequent occurrence, hypersensitivity pneumonitis is often not taken into account in a differential diagnosis of respiratory diseases in children, which leads to a delayed diagnosis despite the characteristic clinical presentation of the disease.

Key words

pulmonary fibrosis, interstitial lung disease, extrinsic allergic alveolitis, precipitins

\section{INTRODUCTION}

Hypersensitivity pneumonitis (HP), formerly called extrinsic allergic alveolitis, is relatively rarely diagnosed in children, but it accounts for approximately $50 \%$ of all forms of interstitial lung disease in this age group [1]. According to Danish report, the prevalence of HP is approximately 4 cases $/ 1$ million children and the incidence is 2 cases/year [2]. HP is most commonly diagnosed in children aged approximately 10 years $[2,3]$ and $25 \%$ had a family history of the disease [4].

\section{OBJECTIVE}

The aim of the study is to present the current state of knowledge on hypersensitivity pneumonitis in children with a focus on the specific aspects of diagnostic investigation in this age group. The study includes a case report with a classic course of the disease.

\section{STATE OF KNOWLEDGE}

Hypersensitivity pneumonitis is defined as a disease with a variable clinical course which involves an IgE-independent hypersensitivity reaction to various environmental factors leading to lymphocytic and granulomatous inflammation

Address for correspondence: Maria Wawszczak, Department of Pediatric Pulmonology and Allergy, Medical University of Warsaw, Poland

E-mail:mwawszczak@wum.edu.pl

Received: 01.12.2019; accepted: 09.03.2020; first published: 08.05.2020 of the peripheral airways, alveoli and the surrounding interstitial tissue.

Aetiology and pathomechanism. The number of known factors causing HP is substantial and constantly growing. They have been divided into 6 groups: bacteria, fungi, animalderived proteins, plant proteins, low molecular weight chemicals and metals $[5,6]$.

The earliest reports of HP cases in children date back to the 1960s and include the terms "pigeon-breeder lung disease" and "farmer's lung disease" [7]. Currently, in the paediatric population, antigens causing HP are usually found in the domestic environment and are associated with pastime activities. The causative agents mainly include avian, fungal and mould or various inorganic antigens, such as inhaled paints, plastics, wax and talcum $[2,4,8,9]$.

Specific antigens eliciting HP include thermophilic actinomycetes, the causative antigen of classic farmer's lung disease. Typically, this form of HP may occur in children who live on a farm [10], but a case associated with periodic exposure in an equestrian centre has also been reported [11]. Thermophilic actinomycetes are present in various organic materials, such as rotting hay, household composts, and sugar cane residue called bagasse; other sources are air-conditioning, air humidifiers and automated water systems. They may be contaminated not only with actinomycetes, but also with other microorganisms, such as Aspergillus sp., Candida sp., Cephalosporium, Aureobasidium pullulans, Naegleria gruberi, Acanthamoeba polyphaga, Acanthamoeba castellani, and Bacillus spp. $[6,12,13,14]$. In such cases, the disease takes the form of HP known as humidifier lung disease. 
An example of the disease associated with exposure to fungi and moulds is a summer-type HP. This is the most common form of the disease in Japan, caused by inhaling Trichosporon sp. or Cryptococcus albidus, which contaminate a warm and humid home environment [15].

The most common form of HP associated with pastime activities is pigeon-breeder lung or bird fancier's disease $[16$, $17,18,19]$. Disease-inducing factors include such proteins as immunoglobulins, intestinal mucin (present in avian faeces) and bloom (a waxy material covering birds' feathers).

Another important etiological factor for $\mathrm{HP}$ is Mycobacterium avium complex inducing a hot-tub lung disease [20]. Mycobacteria are common in the environment: in the soil and water of natural reservoirs, waterworks and artificial reservoirs. They are resistant to temperature changes and disinfectants and the water environment of swimming pools and hot baths is suitable habitat for their survival and colonization.

HP may also be caused by drugs such as rituximab [21], methotrexate [22], azathioprine [23], sertraline [24].

It is intriguing, that cases of the disease associated with an e-cigarette use were also reported $[25,26]$.

Table 1. Selected factors causing hypersensitivity pneumonitis $[5,6,14]$

\begin{tabular}{|c|c|c|}
\hline Antigen & Antigen source & Disease \\
\hline $\begin{array}{l}\text { Mycobacterium avium } \\
\text { complex }\end{array}$ & Contaminated water & Hot-tub lung \\
\hline Thermophilic actinomycetes & Moldy hay, compost & Farmer's lung \\
\hline Bacillus subtilis & Detergent enzymes & Detergent-worker's lung \\
\hline $\begin{array}{l}\text { Naegleria gruberi, } \\
\text { Acanthamoeba sp., } \\
\text { Thermoactinomyces sp., } \\
\text { Candida sp., others }\end{array}$ & $\begin{array}{l}\text { Contaminated water from } \\
\text { home humidifier, } \\
\text { ultrasonic misting fountains }\end{array}$ & Humidifier lung \\
\hline Trichosporon spp. & $\begin{array}{l}\text { Contaminated home } \\
\text { environment }\end{array}$ & $\begin{array}{l}\text { Japanese summer-type } \\
\text { hypersensitivity } \\
\text { pneumonitis }\end{array}$ \\
\hline Animal proteins & $\begin{array}{l}\text { Avian serum and feather } \\
\text { proteins }\end{array}$ & $\begin{array}{l}\text { Pigeon-breeder's lung, } \\
\text { bird-breeder's lung, bird- } \\
\text { fancier's lung }\end{array}$ \\
\hline Acid anhydrides & Plastics & $\begin{array}{l}\text { Plastic worker's lung, } \\
\text { chemical-worker's lung, } \\
\text { epoxy-worker's lung }\end{array}$ \\
\hline Isocyanates & Paints, plastics & Paint-refiniszer's lung \\
\hline Pyrethrum & Insecticide & Insecticide lung \\
\hline
\end{tabular}

The pathophysiology of HP is complex and not well understood. The disease involves lymphocytic and granulomatous inflammation of the peripheral airways, alveoli and surrounding interstitial tissue. Inflammation is a result of type III (immune complexes) and type IV (cellmediated) hypersensitivity reaction caused by repetitive exposure to environmental inhalant allergens [5]. The allergens are small particles with a diameter of less than 5 $\mu \mathrm{m}$, which makes it possible for them to penetrate the alveoli [27]. They may be both organic proteins (plant and animal) and low molecular weight agents.

In acute $\mathrm{HP}$, an inflammatory reaction appears to be mediated by immune complexes, as suggested by the presence of high titres of antigen-specific precipitating IgG in the serum, and an increase in neutrophils in the lungs primed for an enhanced respiratory burst [27].

Subacute and chronic HP are characterized by an exaggerated $\mathrm{T}$ cell-mediated immune response with increased T-cell migration, local proliferation, and decreased apoptosis contributing to the characteristic T-lymphocytic alveolitis
$[14,28,29]$. The immune processes that lead to progression to fibrosis are less clear. However, features associated with chronic $\mathrm{HP}$ include an increase in CD4+ Tcells and in the CD4+/CD8+ ratio, a skewing toward $\mathrm{Th} 2 \mathrm{~T}$-cell differentiation and cytokine profile, as well as an exhaustion of CD8+ T cells [14]. Also, the increase of Th17 cells may promote collagen deposition in the lung in response to chronic exposure of HP antigens.

The role of precipitins in the pathogenesis of the disease is not fully known. They are found in the serum of approximately a half of individuals exposed to a given antigen who do not present any clinical symptoms of the disease [8]. It is suggested that the disease process is based on an individual propensity of the immune system to develop an inflammatory reaction, probably associated with certain major histo-compatibility complex genes [30,31].

One of the factors initiating the disease seems to be viral infections (e.g. RSV, influenza A) [5, 14]. Tobacco smoke seems to have a protective effect against the development of $\mathrm{HP}$, which is probably associated with its immunosuppressive activity, particularly its influence on the production of proinflammatory cytokines by macrophages and inhibition of lymphocyte proliferation [5, 32]. However, a precise pathogenesis of the disease is not known and the aetiology seems to be multi-factorial, i.e. the coincidence of a number of trigger factors in individuals with a genetic predisposition may lead to inflammatory lesions in the lungs [5].

Clinical manifestations. Obtaining a thorough patient history of symptoms plays a key role in diagnosing hypersensitivity pneumonitis and identifying the trigger factor. In the majority of cases, a clinical presentation is characteristic: there are respiratory symptoms, such as dyspnoea during exercise $(94 \%)$ or rest $(52 \%)$, a cough $(52 \%)$ and, less commonly, wheezing (5\%); nearly half of the patients lose weight [2, $3,4]$. On physical examination, apart from the presence of dyspnoea, there are crackles on auscultation (approximately $50 \%$ of children); in some cases signs of bronchial obstruction are noted. In some advanced cases of the disease, digital clubbing may be present (in 10-30\% of children). A clinical presentation may suggest an infection-induced asthma exacerbation or Mycoplasma pneumoniae infection. As a result, inhaled corticosteroids, bronchodilators and macrolide antibiotics are often administered $[2,4]$. The presence of HP is supported by the lack of clinical improvement during the treatment and by the recurrence of symptoms after contact with a specific environmental antigen.

Clinical course. The duration and intensity of exposure to the trigger factor determine the clinical course of the disease [2, 5]. Historically, three forms of hypersensitivity pneumonitis were distinguished: acute, subacute and chronic; however, due to the difficulties in differentiating between the particular forms in clinical practice, experts currently propose a division into two phenotypes $[5,33]$ :

Acute/subacute HP - characterised by recurrent episodes of influenza-like symptoms: fever, muscle pain, cough and dyspnoea. The symptoms develop within $2-9$ hours from contact with a trigger factor and persist for a few hours or days. On a physical examination, bilateral crackles at the base of the lungs are found and signs of bronchial obstruction may be present. A chest radiograph of patients with acute/subacute HP is often normal or shows diffuse air-space consolidation and a nodular or reticulonodular pattern. Symptoms are 
generally caused by an intensive but short exposure to an allergen. They usually subside completely after the end of contact with the trigger factor.

Chronic HP - manifesting with chronic and gradually deteriorating respiratory symptoms and weight loss. Patients with this disease phenotype have an abnormal radiographic image of the lungs and a restrictive or obstructive and restrictive ventilatory defect in pulmonary function tests. The clinical course is determined by a constant but less intensive exposure to a trigger factor, which leads to progressive pulmonary fibrosis, emphysema and secondary pulmonary hypertension. Patients have the symptoms of gradually developing respiratory failure with an accompanying chronic dry cough, or cough with little expectoration, and weight loss. Periods of disease exacerbation may occur manifesting with worsening dyspnoea and lung radiographic image deterioration. Apart from signs of dyspnoea, physical examination reveals crackles at the base of the lungs or over all the pulmonary fields; in $10-30 \%$ of patients, digital clubbing is observed $[2,4,34]$. A chest radiograph usually shows the abnormalities characteristic for pulmonary fibrosis process.

Additional tests. Laboratory tests may show moderate leukocytosis, elevated inflammatory markers (increased C-reactive protein level, accelerated erythrocyte sedimentation rate), and in some cases, increased immunoglobulin IgG and IgA levels [2].

Precipitin assay - is helpful in identifying the trigger factor. However, it needs to be emphasised that the presence of specific IgG antibodies only indicates exposure to a given antigen, but is not a marker of the disease [8]. A positive result is also found in individuals without clinical symptoms of the disease. On the other hand, the lack of specific precipitins does not exclude either exposure to the antigen or HP diagnosis. However, according to some authors, the rate of positive results in children is high - approximately $90 \%$ $[2,34]$.

Diagnostic imaging. In the acute/subacute disease, a chest radiograph mainly shows parenchymal opacities and diffuse poorly defined nodules [5]. A radiographic image may also be normal, particularly in the case of first exposure to an antigen (18-37\% of cases) $[2,34]$. In chronic HP, the chest radiograph is abnormal in $98 \%$ of cases, and persistent reticular and linear opacities predominate $[5,30]$.

In the acute/subacute $\mathrm{HP}$, a high resolution computed tomography (HRCT) shows diffuse ground-glass opacities, mosaic attenuation, poorly defined small centrilobular nodules and air trapping on expiratory CT images $[4,5,35$, 36, 37]. Chronic HP is characterized by the presence of a reticulation and parenchymal distortion due to the fibrosis process; bronchiectasis can also be found [4]. In some cases, mediastinal lymphadenopathy has been reported.

Bronchoalveolar lavage (BAL) - has a lower diagnostic value in the paediatric population than in adults [8]. An increase in the total cell count in BAL with marked lymphocytosis, predominance of CD8+ T cells and a low CD4+/CD8+ ratio, is a characteristic feature of HP in adults [5]. In paediatric patients, BAL lymphocytosis also occurs in all cases, as well as a decreased CD4+/CD8+ ratio $(<1)[3]$. However, an increased CD4+/CD8+ ratio has also been observed [4]. Moreover, the predominance of CD8+cells and a reduced $\mathrm{CD} 4+/ \mathrm{CD} 8+$ ratio in the absence of BAL lymphocytosis may be present in children without interstitial lung disease [38]. All these findings compromise the specificity of this method. Nevertheless, the BAL is an important diagnostic tool which may allow the avoidance of a lung biopsy. According to some authors, the normal BAL cellularity excludes the diagnosis of HP with very high security [37].

Lung function tests - usually show a restrictive ventilatory defect and an associated impaired gas exchange (decreased diffusing capacity for carbon monoxide [DLCO] down to $50-62 \%$ of the predicted value) [2,3]. In reported paediatric cases, spirometric results, such as a vital lung capacity (FVC) and a forced expiratory volume in one second (FEV1), were reduced to approximately $40-53 \%$ of the predicted value [2, $3,4,34]$. In whole-body pletysmography, a decreased value of total lung capacity (TLC) was observed approximately to $60 \%$ of the predicted value with associated air trapping (increased $\mathrm{RV} / \mathrm{TLC}$ ratio). Infrequently, there may be a component of airflow obstruction (decreased FEV1/FVC ratio) related to bronchiolitis $[4,34]$.

Inhalation Provocation Test (IPT) - a relatively rare diagnostic method is an inhalation provocation test, IPT [5]. Owing to difficulties with conducting the procedure and interpreting the results correctly, it is not recommended for routine use. Due to the lack of standardization and because of the risk of severe reactions, the test should be performed exclusively at specialised centres with appropriate experience, and only if other diagnostic methods are not sufficient to determine a diagnosis [27]. According to scientific reports, IPTs are positive in $55 \%$ of cases in the paediatric population [34].

Lung biopsy - is indicated in dubious cases. The histopathological findings of HP are dependent on the stage of the disease, intensity, and duration of antigen exposure. Histologic studies in acute HP are scarce as lung biopsy is generally not necessary for the diagnosis. The main abnormalities include infiltrations of the alveolar spaces and interstitium, mainly with neutrophils, variably associated with the findings of subacute HP $[29,39]$. The pathologic patterns in subacute $\mathrm{HP}$ are predominantly lymphocytic inflammation of the small airways and pulmonary parenchyma, with poorly formed, small non-necrotizing granulomas[40]. The lesions have a peribronchiolar and interlobular location. The typical granulomas of HP consist of a loose collections of histiocytes or scattered giant cells, frequently with cholesterol clefts, or other nonspecific cytoplasmic inclusions, such as Schaumann bodies and oxalate crystals [29]. In chronic HP, the image of interstitial pulmonary fibrosis dominates; in addition, abnormalities characteristic for subacute HP are also usually found. This form of HP should be differentiated from other chronic interstitial lung diseases. The main ancillary features for differentiating are bronchiolocentric localization of fibrotic lesions, the presence of Schaumann bodies, giant multinucleated cells, or small granulomas, and a significant lymphoid/plasmacytic infiltrate [29].

Diagnostic criteria. Currently, there are no separate diagnostic criteria for hypersensitivity pneumonitis in the paediatric population. The clinical presentation of the 
disease (particularly the relationship between symptoms and exposure to a trigger factor) in correlation with a characteristic HRCT image of the lungs, are of crucial importance for the diagnosis. A precipitin assay is helpful in identification of the trigger factor, while a bronchoalveolar lavage makes it possible to determine the cellular composition of lower respiratory tract secretions, and to perform bacteriological tests in order to exclude an infectious origin of the abnormalities. In dubious cases, histopathological assessment of a lung biopsy specimen is helpful.

Current occupational hypersensitivity pneumonitis diagnostic criteria, based on the European Academy of Allergy and Clinical Immunology (EAACI) guidelines of 2016, are presented below [5]. However, the fact needs to be emphasised that their use in children is limited due to difficulties with the performance of pulmonary functional tests and poor availability of provocation tests.

Acute/subacute HP - diagnosis can be established if all the following criteria are met:

- exposure to a potential environmental trigger factor;

- recurrent episodes of symptoms occurring 4-8 hours after exposure to the trigger factor;

- presence of specific precipitins to an occupational antigen;

- presence of inspiratory crackles;

- HRCT image pattern compatible with acute/subacute HP.

If only part of these features are fulfilled, one of the following additional criteria can be used instead:

- bronchoalveolar lavage lymphocytosis;

- pathology of lung specimen characteristic for acute/ subacute HP;

- positive provocation tests or clinical improvement after the end of exposure to the trigger factor, and symptoms recurrence after the renewed exposure.

Chronic HP - diagnosis can be confirmed if four or more of the following criteria are presented:

- exposure to a potential trigger factor in the surrounding environment;

- presence of specific precipitins or bronchoalveolar lavage lymphocytosis;

- decreased DLCO or hypoxaemia at rest or exercise;

- HRCT image pattern consistent with chronic HP;

- pathology of lung specimen characteristic for chronic HP;

- positive provocation tests or clinical improvement after the end of exposure to the trigger factor, and symptom recurrence after renewed exposure.

Differential diagnosis. The diagnosis of acute/subacute HP usually requires differentiation between an acute viral or atypical bacterial respiratory infection and asthma exacerbation [2, 4]. HP diagnosis is supported by the persistence of symptoms despite various treatment regimens (antibiotic therapy, symptomatic inhalation treatment), by their spontaneous resolution after the change of environment, and recurrence after a renewed exposure to the antigen.

Chronic HP should be differentiated from other chronic interstitial lung diseases, and in some cases, with severe, steroidresistant asthma [4]. HP should be suspected particularly in the case of constant exposure to a given environmental factor. An HRCT image is helpful in differential diagnosis. The HRCT findings characteristic for chronic HP include reticulation and parenchymal distortion due to fibrosis process and some findings of subacute form, such as diffuse groundglass opacities and poorly defined small centrilobular nodules [5]. According to certain authors, features strongly indicative for chronic HP in HRCT scan include the predominance of upper lung zone abnormalities, air-trapping, and the presence of more distinct ground-glass opacities [39].

Treatment. The main strategy of hypersensitivity pneumonitis management is to eliminate exposure to the offending factor. This is the only causal treatment of the disease. In acute HP with a mild course, the ending exposure to the antigen usually leads to a complete resolution of symptoms. In cases with a moderate or severe course, systemic corticosteroids should be considered. Oral prednisone therapy is usually used [5]. There are also scarce reports of a methylprednisolone pulse therapy [2] and a budesonide inhalation therapy, although the efficacy of these methods is a matter of dispute due to very limited evidence [41]. In the case of disease progression despite the use of systemic corticosteroids, hydroxychloroquine, cyclosporine, azathioprine or mycophenolate mofetil immunosuppression therapy should be considered $[2,5,42]$.

In advanced cases with extensive pulmonary fibrosis, respiratory failure and secondary pulmonary hypertension, the only effective therapy is lung transplantation. The treatment duration depends on the form of the disease and on clinical, lung function and radiographic improvement. In the case of a good response to treatment, lung capacity parameters gradually improve over the first six months; subsequently, they reach a plateau [43]. In advanced cases with pulmonary fibrosis, the patient's lung function parameters and radiographic image does not usually return to normal.

Prognosis. The prognosis in children with HP is generally perceived as favourable if antigen avoidance is possible $[2,4$, 34]. Elimination of the trigger factor combined with systemic corticosteroids therapy leads to symptom resolution and improvement of pulmonary function [34]. Nevertheless, in the case of significantly delayed diagnosis, the progressive pulmonary fibrosis and development of severe respiratory insufficiency has been reported previously [4]. A longitudinal assessment of children with HP was performed by Sisman et al. [43] in which pulmonary function tests were performed in 22 children during treatment, after the treatment and a few years later. No significant difference was found between the results of tests performed at the end of the treatment and those conducted a few years subsequently. More than $90 \%$ of the patients had normal spirometry results and $86 \%$ had a normal total lung capacity value. However, despite normal physical fitness, in $41 \%$ of the cases an impaired gas exchange was observed (decreased DLCO), and abnormalities in peripheral airways function were found in nearly a half of the patients in a multiple breath nitrogen washout test.

\section{CASE REPORT}

A 14-year-old boy with a positive family history for allergy (asthma in the mother) was admitted to hospital due to suspected hypersensitivity pneumonitis. The medical history revealed that the boy had constant daily contact with birds: he lived in the countryside in a detached house near a pigeon loft. There had previously been chickens on the farm, and 
a canary in the family house. At the time of admission, the patient had a 3-month history of productive cough, signs of dyspnoea, periodic wheezing and exercise intolerance. Symptoms suggesting an acute respiratory infection (fever, muscle pain, exacerbated cough and dyspnoea) were observed twice following the boy's contact with pigeon faeces during loft cleaning. The symptoms subsided within 24 hours from the end of exposure. The treatment regimen included antihistamines, antileukotriens, bronchodilators and inhaled anti-inflammatory drugs; however, without any clinical improvement. Respiratory symptoms persisted and weight loss was additionally observed.

The boy was hospitalised at another hospital for diagnosis of the above-mentioned symptoms. Physical examination revealed crackles at the base of the right lung; basic laboratory tests did not reveal any significant abnormalities, while allergy tests showed signs of atopy (high total IgE level, positive skin prick tests for mugwort allergens). Chest X-ray was normal, while spirometry revealed abnormal lung capacity values, suggesting some signs of mild restriction. Since a relationship was established between the symptoms and exposure to pigeon faeces antigens, hypersensitivity pneumonitis was suspected. The boy was referred for further specialist diagnostic procedures and advised to completely avoid any contact with birds. After exposure to the suspected trigger factor was eliminated, a clinical improvement was observed in the partial resolution of respiratory symptoms.

Upon admission, the patient was in a good health condition, although he complained of mild dyspnoea and productive cough. Physical examination and basic laboratory tests did not reveal any significant abnormalities, apart from elevated levels of all classes of immunoglobulin. Pulmonary function tests demonstrated restriction patterns combined with a bronchial obstruction and impaired gas exchange expressed as decreased DLCO. HRCT revealed characteristic radiological patterns consistent with HP: generalised interlobular peri-bronchiolar thickening producing a discrete reticular opacities, and poorly defined centrilobular and subpleural nodules.

As part of a differential diagnosis, bronchofiberoscopy was performed with bronchoalveolar lavage, which revealed a substantial predominance of lymphocytes ( $>80 \%$ of all cells) with a decreased CD4+/CD8+ lymphocyte ratio. Positive precipitin reactions on bird breeder's disease test (using Ouchterlony agar gel double diffusion technique and antigens from pigeon, duck, turkey and parrot faeces) supported a relationship between exposure to the suspected trigger factor and the disease symptoms. A subacute HP was diagnosed. The family was advised to completely eliminate bird antigens from the child's environment, and oral corticosteroids therapy was started. Systematic improvement in the patient's clinical condition and pulmonary function parameters was observed.

In the case reported above, the diagnosis of hypersensitivity pneumonitis was made early (within three months from the onset of symptoms) due to a characteristic clinical presentation and correlation of symptoms with an exposure to bird faeces antigens. Respiratory symptoms predominated. There was periodic exacerbation of the disease in the form of short episodes of influenza-like symptoms, and more intense coughing caused by massive exposure to the trigger factor. It is worth noting that the suspicion of a correct diagnosis had already been made before a specialist diagnostic
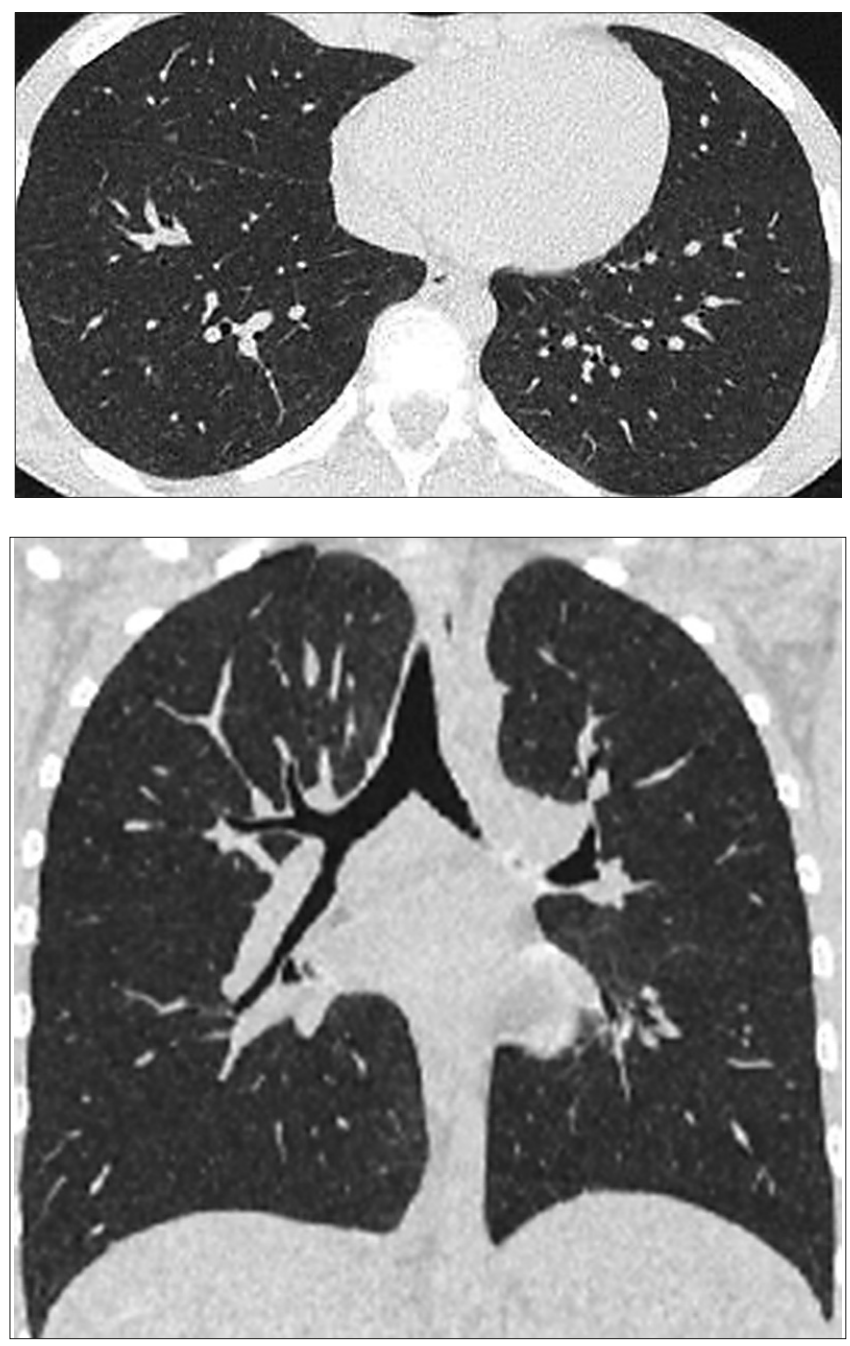

Figure 1. High-resolution computed tomography of the chest. Coronal and transverse section. Generalised discrete reticular opacities and poorly defined centrilobular and subpleural nodules

investigation was performed. The advice to stop exposure to the suspected trigger factor, i.e. pigeon faeces antigens, had a crucial influence on the further course of the disease and the patient's prognosis.

\section{CONCLUSIONS}

Hypersensitivity pneumonitis is a rare, but not exceptional condition in children, and it is often associated with exposure to antigens at home and during the child's pastime activities. The diagnosis of paediatric HP is difficult and presents even more of a challenge than in adults. It relies on the combination of exposure history, characteristic clinical presentation of the disease, and some additional tests abnormalities, none of which is actually specific, including histopathological assay.

Since the HP symptoms may mimic recurrent acute respiratory infection and asthma exacerbation, it should be considered in a patient presenting with prolonged or recurrent cough, or dyspnea without obvious trigger factors.

The prognosis of HP in children is generally perceived as good if antigen avoidance is possible. Nevertheless, in a case of significant delayed diagnosis, progressive pulmonary fibrosis may be present. 


\section{REFERENCES}

1. Griese M. Chronic interstitial lung disease in children. Eur Respir Rev. 2018 Feb 7; 27(147). pii: 170100. https://doi.org/10.1183/16000617.01002017

2. Buchvald F, Petersen BL, Damgaard K, Deterding R, Langston C, Fan LL, et al. Frequency, treatment, and functional outcome in children with hypersensitivity pneumonitis. Pediatr Pulmonol. 2011 Nov; 46(11): 1098-107. https://doi.org/10.1002/ppul.21479

3. Wanin S, Malka-Ruimy C, Deschildre A, Nathan N, Reboux G, Reix P, et al. Usefulness of bronchoalveolar lavage in a French pediatric cohort with hypersensitivity pneumonitis. Pediatr Pulmonol. 2019 Oct 20. https://doi.org/10.1002/ppul.24546

4. Griese M, Haug M, Hartl D, Teusch V, Glöckner-Pagel J, Brasch F; National EAA Study Group. Hypersensitivity pneumonitis: lessons for diagnosis and treatment of a rare entity in children. Orphanet J Rare Dis. 2013; 8: 121. https://doi.org/10.1186/1750-1172-8-121

5. Quirce S, Vandenplas O, Campo P, Cruz MJ, de Baly F, Koschel D, et al. Occupational hypersensitivity pneumonitis: an EAACI position paper. Allergy. 2016; 71(6): 765-79. https://doi.org/10.1111/all.12866

6. Riario Sforza GG, Marinou A. Hypersensitivity pneumonitis: a complex lung disease. Clin Mol Allergy. 2017; 15: 6. https://doi.org/10.1186/ s12948-017-0062-7

7. Soumagne T, Dalphin ML, Dalphin JC. Hypersensitivity pneumonitis in children. Rev Mal Respir. 2019; 36(4): 495-507. https://doi.org/10.1016/j. rmr.2018.06.010

8. Nathan N, Berdah L, Borensztajn K, Clement A. Chronic interstitial lung diseases in children: diagnosis approaches. Expert Rev Respir Med. 2018; 12(12): 1051-1060. https://doi.org/10.1080/17476348.2018.1538795

9. Magon P. Reversible lung disease due to abundant use of talcum powder. Indian J Pediatr. 2012; 79(10): 1383. https://doi.org/10.1007/s12098 012-0713-0

10. Aebischer CC, Frey U, Schöni MH. Hypersensitivity pneumonitis in a five-year-old boy: an unusual antigen source. Pediatr Pulmonol. 2002; 33(1): 77-8. https://doi.org/10.1002/ppul.10020

11. Kristiansen JD, Lahoz AX. Riding-school lung? Allergic alveolitis in an 11-year-old girl. Acta Paediatr Scand. 1991; 80(3): 386-8. https:// doi.org/10.1111/j.1651-2227.1991.tb11868.x

12. Fracchia MS, El Saleeby CM, Murali MR, Sagar P, Mino-Kenudson M. Case records of the Massachusetts General Hospital. Case 9-2013. A 9-year-old boy with fever, cough, respiratory distress, and chest pain. N Engl J Med. 2013; 368(12): 1141-50. https://doi.org/0.1056/ NEJMcpc1208144

13. Ando A, Hagiya H, Nada T, Kimura K, Waseda K, Rai K, et al. Hypersensitivity Pneumonitis Caused by a Home Ultrasonic Humidifier Contaminated with Candida guilliermondii. Intern Med. 2017; 56(22): 3109-3112. https://doi.org/10.2169/internalmedicine.9055-17

14. Selman M. Immunopathology, diagnosis, and management of hypersensitivity pneumonitis. Semin Respir Crit Care Med. 2012; 33(5): 543-54. https://doi.org/10.1055/s-0032-1325163

15. Asai N, Kaneko N, Ohkuni Y, Aoshima M, Kawamura Y. Familial Summer-type hypersensitivity Pneumonitis: A Review of 25 Families and 50 Cases in Japan. Intern Med. 2016; 55(3): 279-83. https://doi. org/10.2169/internalmedicine.55.5121

16. Tsanglao WR, Nandan D, Chandelia S, Bhardwaj M. Chronic Hypersensitivity Pneumonia due to Pigeon Breeders Disease. Indian Pediatr. 2017; 54(1): 55-57. https://doi.org/10.1007/s13312-017-0999-0

17. Cardoso J, Carvalho I. The value of family history in the diagnosis of hypersensitivity pneumonitis in children. J Bras Pneumol. 2014; 40(2): 183-7. https://doi.org/10.1590/s1806-37132014000200013

18. Habra B, AbdulWahab A. A Rare Pediatric Case of Severe Bird Fancier's Lung Presented with Viral Pneumonitis-Like Picture. Children (Basel) 2018; 5(11): 149. https://doi.org/10.3390/children5110149

19. Jordan LE, Guy E. Paediatric feather duvet hypersensitivity pneumonitis. BMJ Case Rep. 2015; 2015.pii: bcr2014207956. https://doi.org/10.1136/ bcr-2014-207956

20. Vergez M, Honjoya S, Guérin S, Delacourt C, Benoist G. Hot tub lung: A case report. Arch Pediatr. 2017; 24(12): 1271-1274. https://doi. org/10.1016/j.arcped.2017.09.001

21. Naqibullah M, Shaker SB, Bach KS, Bendstrup E. Rituximab-induced interstitial lung disease: five case reports. Eur Clin Respir J. 2015;2. https://doi.org/10.3402/ecrj.v2.27178

22. Fragoulis GE, Conway R, Nikiphorou E. Methotrexate and interstitial lung disease: controversies and questions. A narrative review of the literature. Rheumatology (Oxford). 2019; 58(11): 1900-1906. https:// doi.org/10.1093/rheumatology/kez337
23. Lee IH, Kang GW, Kim KC. Hypersensitivity pneumonitis associated with azathioprine therapy in a patient with granulomatosis with polyangiitis. Rheumatol Int. 2016; 36(7): 1027-32. https://doi. org/10.1007/s00296-016-3489-0

24. Virdee G, Bleasdale J, Ikramullah M, Graham-Clarke E. Sertralineinduced hypersensitivity pneumonitis. BMJ Case Rep. 2019; 12(12). pii: e230724. https://doi.org/ 10.1136/bcr-2019-230724

25. Sommerfeld CG, Weiner DJ, Nowalk A, Larkin A. Hypersensitivity Pneumonitis and Acute Respiratory Distress Syndrome From E-Cigarette Use. Pediatrics. 2018; 141(6). pii: e20163927. https://doi. org/10.1542/peds.2016-3927

26. Nair N, Hurley M, Gates S, Davies P, Chen IL, Todd I, et al. Lifethreatening hypersensitivity pneumonitis secondary to e-cigarettes. Arch Dis Child. 2019; pii: archdischild-2019-317889. https://doi. org/10.1136/archdischild-2019-317889

27. Selman M, Pardo A, King TE. Jr. Hypersensitivity pneumonitis: insights in diagnosis and pathobiology. Am J Respir Crit Care Med. 2012; 186(4): 314-24. https://doi.org/ 10.1164/rccm.201203-0513C

28. Greenberger PA. Hypersensitivity pneumonitis: A fibrosing alveolitis produced by inhalation of diverse antigens. J Allergy Clin Immunol. 2019; 143(4): 1295-1301. https://doi.org/10.1016/j.jaci.2018.09.040

29. Spagnolo P, Rossi G, Cavazza A, Bonifazi M, Paladini I, Bonella F, et al. Hypersensitivity Pneumonitis: A Comprehensive Review. J Investig Allergol Clin Immunol. 2015; 25(4): 237-50; quiz follow 250

30. Soumagne T, Dalphin JC. Current and emerging techniques for the diagnosis of hypersensitivity pneumonitis. Expert Rev Respir Med. 2018; 12(6): 493-507. https://doi.org/10.1080/17476348.2018.1473036

31. Falfán-Valencia R, Camarena A, Pineda CL, Montaño M, Juárez A, Buendía-Roldán I, et al. Genetic susceptibility to multicase hypersensitivity pneumonitis is associated with the TNF-238 GG genotype of the promoter region and HLA-DRB1*04 bearing HLA haplotypes. Respir Med. 2014; 108(1): 211-7. https://doi.org/10.1016/j. rmed.2013.11.00

32. Peiffer G, Underner M, Perriot J. The respiratory effects of smoking. Rev Pneumol Clin. 2018; 74(3): 133-144. https://doi.org/10.1016/j. pneumo.2018.04.009

33. Vasakova M, Morell F, Walsh S, Leslie K, Raghu G. Hypersensitivity Pneumonitis: Perspectives in Diagnosis and Management. Am J Respir Crit Care Med. 2017; 196(6): 680-689. https://doi.org/10.1164/ rccm.201611-2201PP

34. Fan LL. Hypersensitivity pneumonitis in children. Curr Opin Pediatr. 2002; 14(3): 323-6. https://doi.org/10.1097/00008480-200206000-00008

35. Walsh SLF, Richeldi L. Demystifying fibrotic hypersensitivity pneumonitis diagnosis: it's all about shades of grey. Eur Respir J. 2019; 54(1). pii: 1900906. https://doi.org/10.1183/13993003.00906-2019

36. Semple TR, Ashworth MT, Owens CM. Interstitial Lung Disease in Children Made Easier...Well, Almost. Radiographics. 2017; 37(6): 1679-1703.https://doi.org/10.1148/rg.2017170006

37. Bush A, Cunningham S, de Blic J, Barbato A, Clement A, Epaud R, et al. chILD-EU Collaboration. European protocols for the diagnosis and initial treatment of interstitial lung disease in children. Thorax. 2015; 70(11): 1078-84. https://doi.org/10.1136/thoraxjnl-2015-207349

38. Ratjen F, Bredendiek M, Zheng L, Brendel M, Costabel U. Lymphocyte subsets in bronchoalveolar lavage fluid of children without bronchopulmonary disease. Am J Respir Crit Care Med. 1995; 152: 174-178. https://doi.org/10.1164/ajrccm.152.1.7599820

39. Churg A, Bilawich A, Wright JL. Pathology of Chronic Hypersensitivity Pneumonitis What Is It? What Are the Diagnostic Criteria? Why Do We Care? Arch Pathol Lab Med. 2018; 142(1): 109-119. https://doi.org/ 10.5858/arpa.2017-0173-RA

40. Miller R, Allen TC, Barrios RJ, Beasley MB, Burke L, Cagle PT, et al. Hypersensitivity Pneumonitis A Perspective From Members of the Pulmonary Pathology Society. Arch Pathol Lab Med. 2018; 142(1): 120-126. https://doi.org/10.5858/arpa.2017-0138-SA

41. Carlsen KH, Leegaard J, Lund OD, Skjaervik H. Allergic alveolitis in a 12 -year-old boy - treatment with budesonide nebulizing solution. Pediatr Pulmonol. 1992, 12(4): 257-259. https://doi.org/10.1002/ ppul.1950120411

42. Fiddler CA, Simler N, Thillai M, Parfrey H. Use of mycophenolate mofetil and azathioprine for the treatment of chronic hypersensitivity pneumonitis-A single-centre experience. Clin Respir J. 2019; 13(12): 791-794. https://doi.org/10.1111/crj.13086

43. Sisman Y, Buchvald F, Blyme AK, Mortensen J, Nielsen KG. Pulmonary function and fitness years after treatment for hypersensitivity pneumonitis during childhood. Pediatr Pulmonol. 2016; 51(8): 830-7. https://doi.org/10.1002/ppul.23360 